\title{
O ENSINO DA GINÁSTICA DE ITATIBA/SP: de volta às escolas
}

\author{
Cibelle Amade Carride' \\ Cintia de Souza Moura² \\ Laurita Marconi Schiavon ${ }^{3}$ \\ Marco Antonio Coelho Bortoleto4
}

\section{RESUMO}

Estudos realizados nos últimos 25 anos apresentam uma diminuição do ensino da Ginástica na Educação Física escolar. Na busca de um diagnóstico atualizado, a pesquisa analisou o ensino da Ginástica nas escolas da cidade de Itatiba-SP, a fim de conhecer as dificuldades bem como as estratégias pedagógicas utilizadas. Os dados foram obtidos por meio de questionário semiestruturado, respondido por 40 professores $(73 \%$ do total) de Educação Física das redes de ensino municipal, estadual e particular do município. Os resultados revelam que a maioria dos profissionais ensina Ginástica na escola, com estratégias de adaptação de materiais/espaço. Os professores que não incluem ginástica em suas aulas relatam não se sentirem preparados, principalmente devido a uma formação inicial insuficiente. A pesquisa indica uma tendência contrária à apontada pela literatura, e sugere a necessidade de formação continuada e suporte didático aos docentes.

Palavras-chave: Ginástica. Educação Continuada. Docentes.

1 Licenciada em Educação Física. professora da Secretaria de Educação da Prefeitura Municipal de Itatiba. Itatiba/ São Paulo, Brasil. E-mail: cicarride@yahoo.com.br

2 Mestre em Atividade Física, Adaptação e Saúde. Professora da Faculdade de Educação Física da Universidade Estadual de Campinas (FEF/UNICAMP) e professora de Educação Física do Colégio Bom Jesus. Itatiba/ São Paulo, Brasil. E-mail: cintiamoura@hotmail.com

3 Doutora em Educação Física. Professora da Faculdade de Educação Física da Universidade Estadual de Campinas (FEF/UNICAMP). Campinas/São Paulo, Brasil. E-mail: laurita@fef.unicamp.br

4 Doutor em Educação Física. Professor do Departamento de Educação Física e Humanidades da Faculdade de Educação Física da Universidade Estadual de Campinas (FEF/UNICAMP). Campinas/São Paulo, Brasil.

E-mail: bortoleto@fef.unicamp.br 


\title{
GYMNASTICS EDUCATION OF ITATIBA/SP: back to school
}

\begin{abstract}
Studies from the last 25 years, has presented a significant decrease in Gymnastics approach in Physical Education (PE) classes at regular school. Searching for updated diagnoses, this research analyzed the teaching of gymnastics in schools of Itatiba-SP in order to understand the difficulties and the pedagogical strategies applied. The data have been collected by a semi-structured questionnaire answered by 40 PE teachers $(73 \%$ of total) of county schools, as well as state and private schools of this area. The results revealed that the majority of the professionals teach gymnastics by adapting materials and spaces. Educators who do not include gymnastics in their classes reported not feeling well prepared to teach by not having enough education. This research shows an opposite trend to those being pointed out by the literature, and for so, suggest the need of continuing education and didactic support for the teachers.
\end{abstract}

Keywords: Gymnastics. Education Continuing. Faculty.

\section{LA ENSEÑANZA DE LA GIMNASIA DE ITATIBA/SP: de vuelta a la escuela}

\begin{abstract}
RESUMEN
Estudios en los últimos 25 años revelan una diminución de la enseñanza de la Gimnasia en la Educación Física escolar. Buscando un diagnostico actualizado, la presente investigación analizó la enseñanza de la gimnasia en escuelas de la ciudad de Itatiba$\mathrm{SP}$, con el objetivo de conocer las dificultades así como las estrategias pedagógicas empleadas. Los datos fueran obtenidos por medio de cuestionario semiestructurado, contestado por 40 profesores (73\% del total) de Educación Física de las redes de enseñanza municipal, estatal y privada de Itatiba. Los resultados revelan que la mayoría de los profesionales enseñan gimnasia en la escuela, adaptando materiales y/o el espacio. Los profesores que no incluyen la gimnasia en sus clases relataron no se sintieren preparados, principalmente debido a una formación inicial insuficiente. La investigación señala una tendencia contraria a la disponible en la literatura, y sugiere la necesidad de formación continuada y mayor soporte didáctico a los docentes.
\end{abstract}

Palabras clave: Gimnasia. Educación Continua. Docentes. 


\section{INTRODUÇÃO}

A ginástica, assim como o esporte, o jogo, a luta e a dança, faz parte dos conteúdos tradicionais, também denominados "clássicos", da Educação Física brasileira, compondo parte fundamental da cultura corporal de movimento (COLETIVO DE AUTORES, 1992). Além disso, prática da ginástica tem revelado importante contribuição para o desenvolvimento das crianças, principalmente nos primeiros anos da educação formal (GERLING, 2009; NISTA-PICCOLO; MOREIRA, 2012).

A relevância da ginástica para a educação física contemporânea pode ser observada ainda a partir da análise das propostas curriculares oferecidas pelos estados, como do Paraná (2008) e de São Paulo (2008), por exemplo, bem como pelo destaque dado recentemente no Programa Segundo Tempo do Governo Federal (2011).

A presença da ginástica nos programas pedagógicos dos professores de Educação Física, particularmente no ensino fundamental e médio foi objeto de diversos estudos (AYOUB, 1998; BONETTI, 1999; POLITO, 1998; SCHIAVON, 2003; SCHIAVON; NISTA-PICCOLO, 2007), as quais em conjunto com outras pesquisas realizadas entre as décadas de 1990 e 2000 (AYOUB, 1998; NISTA-PICCOLO, 1988; RINALDI; SOUZA, 2003; SCHIAVON, 2003) revelaram a diminuição do ensino da ginástica no âmbito escolar. Na opinião de Schiavon e Nista-Piccolo (2006), esse fato vinha acontecendo não só pela ausência de equipamento e material específico, mas também pela falta de preparo dos professores e de conhecimentos adequados, especialmente sobre suas possibilidades pedagógicas, distantes dos conteúdos do alto rendimento que a mídia apresenta.

Rinaldi e Souza (2003, p. 171) afirmam existir um "ciclo vicioso" no qual o desconhecimento da ginástica "se constitui e se afirma", e "que a universidade reproduz a escola que por sua vez reproduz a formação profissional". Ou seja, os alunos não têm contato com esse conteúdo na escola, formam-se na universidade como professores de Educação Física com pouco contato - ou muitas vezes de forma inadequada - com a Ginástica e, consequentemente, acabam por não dar espaço para a Ginástica nas suas aulas nas escolas, dando continuidade ao ciclo, que tende a afastar ainda mais a ginástica da educação física escolar.

Schiavon (2003), a partir de uma pesquisa junto a professores das escolas públicas e particulares da rede de ensino de Campinas-SP, ressalta que esse conteúdo não pode ser apresentado ao aluno apenas por "fazer por fazer", mas, sim, dentro de um contexto, que dê um significado para essa prática pedagógica e considere o aluno como elemento central do processo de ensino. Nessa perspectiva a Ginástica deve ser desenvolvida nas aulas de Educação Física de modo a conquistar os alunos, como adverte Nista-Piccolo (2005). Para isso, é importante um planejamento adequado, além de tornar o conteúdo interessante ao aluno fomentando a descoberta, a ludicidade, e as possibilidades da Ginástica como um saber amplo e abrangente (RUSSEL; NUNOMURA, 2002). Vê-se então que o trato rigoroso com os saberes da Ginástica são fundamentais para que os problemas apontados anteriormente sejam superados. 
Nesse contexto a presente pesquisa objetivou analisar o ensino da Ginástica nas aulas de Educação Física em instituições públicas e privadas de ensino fundamental e médio do município de Itatiba-SP, com o propósito de destacar as principais dificuldades encontradas pelos docentes, bem como conhecer as estratégias utilizadas para desenvolvimento de suas aulas.

\section{MÉTODO}

Do ponto de vista metodológico, esta pesquisa foi elaborada sob uma perspectiva qualitativa, propondo dessa forma uma abordagem descritiva (THOMAS; NELSON, 2002).

Foi elaborado um questionário semiestruturado, baseado no estudo realizado por Schiavon (2003) com perguntas abertas e fechadas pertinentes ao objetivo da pesquisa, o qual foi aplicado a professores de EFE das instituições municipais, estaduais e particulares do município de Itatiba-SP.

O município de Itatiba foi escolhido por caracterizar-se como um típico município de pequeno porte do estado de São Paulo, cujas características podem ser "comparadas" a diversas outras cidades; por existirem ali diversos cursos superiores de Educação Física; por ter uma importante tradição no âmbito da ginástica; e, principalmente, por não haver dados dessa natureza na região.

A referida cidade, de acordo com a Secretaria Municipal de Educação, possui 43 escolas de ensino fundamental e médio, sendo 29 municipais, 5 estaduais e 9 particulares, com um total de 55 professores 5 de Educação Física nas escolas na cidade de Itatiba. As escolas municipais de Itatiba possuem 41 professores de Educação Física, sendo que 32 deles se dispuseram a participar da pesquisa (78\% dos professores). As escolas estaduais possuem 12 professores de Educação Física, dos quais 9 responderam ao questionário (75\%). Já nas escolas particulares, dos 11 professores de Educação Física, 8 deles aceitaram participar (73\%). Portanto, efetivamente, participaram da presente pesquisa 40 professores 6 (73\% dos professores de Itatiba) de 43 escolas (municipais, estaduais e particulares), ou seja, $100 \%$ das escolas da cidade, somando-se um total de 49 questionários, pois dos 40 professores que se dispuseram a colaborar, 9 deles trabalham em duas redes e responderam um questionário para cada uma delas. Os professores participantes da pesquisa estavam regularmente atuantes nas escolas do referido município no ano letivo de 2013.

Os dados qualitativos foram organizados e analisados por meio da Análise de Conteúdo, conforme os pressupostos indicados por Bardin (2011), que podem ser sintetizados nas seguintes etapas: pré-análise; exploração do material; tratamento dos resultados, a inferência e a interpretação. A primeira é uma fase de organização, com o objetivo de operacionalizar e sistematizar as ideias iniciais. A segunda acontece logo após a pré-análise

5 Nove dos professores trabalham em duas redes de ensino.

6 Os demais professores de Educação Física não foram entrevistados devido a afastamentos, liberação por licença de qualquer natureza ou porque não foram encontrados no período de coleta dos dados. 
e tem como finalidade a sistematização das decisões previamente tomadas. Nesse momento ocorre, de fato, a codificação, classificação e categorização dos dados coletados. A terceira e última fase é quando os dados são interpretados, com base em operações estatísticas simples ou complexas, condensando e evidenciando as informações fornecidas pela análise (BARDIN, 2011). Os dados quantitativos foram tratados por estatística descritiva (THOMAS; NELSON, 2002).

A presente pesquisa foi aprovada pelo Comitê de Ética em Pesquisa (CEP), da Faculdade de Ciências Médicas, da Universidade Estadual de Campinas, com o parecer de número 403.629 e, de acordo com as exigências, foi obtido o consentimento de todos os participantes para a pesquisa.

\section{RESULTADOS E DISCUSSÃO}

\section{Perfil dos participantes}

Primeiramente foi realizada a análise relacionada à identificação dos professores de Educação Física de Itatiba, caracterizada por: ano de conclusão da graduação e instituição do ensino superior; número de escolas que lecionam em cada rede de ensino; qual o nível de ensino; e há quanto tempo atuam como professor em escolas.

De acordo com os dados coletados, dos 40 docentes entrevistados, $88 \%$ se formaram em instituições de ensino superior particular. Em relação ao ano de formação, nota-se uma concentração maior dos docentes que se formaram depois de 2001 (73,5\%), conforme exposto na Tabela 1.

Tabela 1 - Ano de conclusão do curso superior em Educação Física dos professores de EFE do município de Itatiba.

\begin{tabular}{cc}
\hline Ano & Porcentagem (\%) \\
\hline até 1980 & 5,0 \\
1981 a 1990 & 12,5 \\
1991 a 2000 & 10 \\
2001 a 2010 & 62,5 \\
2011 a 2012 & 10,0 \\
\hline
\end{tabular}

Embora sejam poucos os docentes que finalizaram a formação inicial nas décadas de 1970 e 1980 e aqueles cujo término é recente, em 2012, por exemplo, revela-se aí uma importante heterogeneidade nesse aspecto temporal, e, por conseguinte, na experiência como docente.

Esses dados levantados suscitam uma importante reflexão. Muitos dos professores formados nas décadas de 1970 e 1980 tiveram uma formação mais tecnicista, considerando o momento histórico e as produções acadêmicas do referido momento. A partir da década 
de 1990, influenciados por discussões pedagógicas acerca da EFE, produções acadêmicas, publicações, e professores universitários mais bem qualificados para a docência no ensino superior, as aulas passam a ter uma ênfase no aspecto pedagógico, o que, no caso da Ginástica, refletirá de forma bastante diferente nas escolas (SCHIAVON, 2003).

Em relação ao tempo em que cada professor atua nas escolas, registrou-se uma ampla variação: entre 1 a 33 anos. As maiores frequências foram entre 1 a 10 anos de experiência, como se pode observar na Tabela 2.

Tabela 2 - Tempo de atuação dos professores na EFE nas escolas de Itatiba-SP.

\begin{tabular}{cc}
\hline Quantidade de anos & Porcentagem (\%) \\
\hline Um a Quatro & 37,5 \\
Cinco a Dez & 32,5 \\
Onze a vinte & 15,0 \\
Vinte e um a trinta & 12,5 \\
Mais que trinta & 2,5 \\
\hline
\end{tabular}

Analisando os dados da Tabela 2, foi constatado que $62,5 \%$ do quadro de professores pesquisados apresentam mais de cinco anos de experiência profissional, o que indica, portanto, a necessidade de formação continuada em busca de atualização e renovação pedagógica (FERREIRA; SANTOS; COSTA, 2015).

Com respeito às redes de ensino que os professores lecionam (municipal, estadual ou particular), observa-se que $80 \%$ dos professores participantes atuam em escolas municipais; $23 \%$ em escolas estaduais; e outros $20 \%$ na rede privada. Foi observado, ainda, que $20 \%$ dos professores lecionam em diferentes redes de ensino. De todo modo, a atuação no ensino público é preponderante nessa localidade.

No que se refere ao nível de ensino, foi considerado se o docente leciona no ensino fundamental e/ou ensino médio. Assim sendo, 77,5\% informaram trabalhar no ensino fundamental I ( $1^{\circ}$ ao $5^{\circ}$ ano), $83 \%$ no ensino fundamental II ( $6^{\circ}$ ao $9^{\circ}$ ano) e $25 \%$ no ensino médio ( $1^{\circ}$ ao $3^{\circ}$ ano). Em alguns casos, há professores que lecionam em mais de um nível de ensino. É, precisamente, no ensino fundamental (I e II), onde se espera que a Ginástica seja um dos conteúdos ensinados, como revela a proposta curricular do estado de São Paulo (SÃO PAULO, 2008).

\section{A Ginástica faz parte das aulas de Educação Física escolar?}

Em relação à presença da Ginástica nas aulas de Educação Física escolar, 77,5\% dos professores participantes afirmaram que ela está entre os conteúdos de suas aulas, sendo apenas 22,5\% os que responderam negativamente. Esse resultado aponta para um quadro positivo se comparado principalmente com as décadas de 1980, 1990 e início do século XXI, quando havia uma ausência ou uma baixa frequência da Ginástica nas aulas de Educação Física. 
Muitas foram as dificuldades apresentadas pelos professores para justificar o porquê de não trabalharem a Ginástica nas suas aulas.

\section{Dificuldades e alternativas: materiais e espaço}

Para a parcela dos professores (22,5\%) que não incluem a Ginástica como conteúdo em suas aulas, $77,8 \%$ justifica esse quadro pela falta de material. Embora os professores que ministram aulas de Ginástica mencionem essa mesma dificuldade, eles revelam suas estratégias para superar esse entrave, como: adaptação, empréstimo e até mesmo fabricação artesanal dos materiais. A falta de material continua sendo uma dificuldade, assim como já abordado em estudos anteriores (NISTA-PICCOLO, 1988; POLITO, 1998; SCHIAVON, 2003), porém isso não poderia ser um impedimento para que as aulas acontecessem, até mesmo porque muitos dos conteúdos gímnicos não necessitam de materiais para o seu desenvolvimento.

Schiavon (2003) propõe alternativas outras para também minimizar essa dificuldade, ou seja, os materiais desmontáveis que não descaracterizam a Ginástica Artística (aparelhos de suspensão, equilíbrio, salto e solo) ou, no caso da Ginástica Rítmica, são fáceis de construir e também de baixo custo (SCHIAVON, 2005; SCHIAVON; NISTA-PICCOLO, 2010). A possibilidade de esses materiais serem desmontáveis vem ao encontro da necessidade de as quadras da escola serem usadas para outras atividades, e ser esse, muitas vezes, o único espaço para práticas corporais.

Lopes (2012) e Macedo (2012) abordam ainda a possibilidade de elaboração e confecção de aparelhos da Ginástica Rítmica e Ginástica Artística, sugerindo que essas construções, de simples elaboração, aconteçam nas disciplinas gímnicas da universidade. Isso acarretaria um custo muito abaixo do material oficial e seria uma excelente oportunidade para professores e alunos de Educação Física, juntos, nas aulas, criarem seus próprios materiais e enriquecerem todo o processo de aprendizagem. Dentre esses equipamentos, encontram-se colchão, plinto, trave de equilíbrio, minitrampolim e barra fixa. Esses estudos mostram que há alternativas viáveis para contornar o problema da falta de materiais oficiais e realizar a Ginástica na escola: criatividade e boa vontade.

Assim como mencionado anteriormente, há a possibilidade de aulas em que a Ginástica pode ser trabalhada em seus fundamentos, sem a necessidade de materiais/aparelhos específicos/oficiais. Nista-Piccolo e Moreira (2012) refletem que materiais propostos para as aulas de ginástica nos anos iniciais do ensino fundamental, como colchões, cones, cordas, plintos, bancos suecos, bolas, arcos, são de fácil acesso na maioria das localidades. Além disso, Schiavon e Nista-Piccolo (2006) afirmam que a falta de materiais pode ser suprida ou "contornada", quando há conhecimento e domínio sobre a Ginástica, com muitas possibilidades criativas de alternativas para seu ensino.

No que se refere ao ensino da Ginástica para Todos (GPT), vertente não competitiva e coletiva de Ginástica, os materiais "não oficiais" ou alternativos são frequentemente utilizados, o que facilita a proposta e soluciona problemas relacionados à falta de 
materiais na escola. Aliás, o aspecto mais importante para esse tipo de prática é a criatividade (BERTOLINI, 2005), facilitando assim seu trato em escolas que não possuem materiais específicos para a Ginástica (AYOUB, 2007).

A falta de espaço ou a disponibilidade de espaço insuficiente/inadequado para a prática foi apontada, como outra importante dificuldade, por $22 \%$ dos professores daqueles que não trabalham a Ginástica nas suas aulas. No entanto, verificou-se que todas as escolas do município possuem quadras poliesportivas. Possivelmente o desconhecimento que os professores têm das diversas possibilidades de Ginástica existentes faz com que alguns docentes não percebam essas quadras como um espaço para a sua prática da ginástica, como Schiavon (2003) já havia observado em suas pesquisas.

\section{Dificuldades e alternativas: desinteresse dos alunos}

O desinteresse dos alunos foi apontado por 33\% das respostas como um fator que dificulta o ensino da Ginástica. Talvez isso se deva ao desconhecimento e à distância que a maior parte das manifestações gímnicas tenha na cultura corporal atual, e, por isso, as aulas têm privilegiado modalidades esportivas como futebol, voleibol e basquetebol (DA SILVA, 2013). Essa visão dos alunos pode estar relacionada também com a falta de informação e interesse do professor, o qual alia o conhecimento da modalidade ao esporte espetáculo, com acrobacias complexas (NISTA-PICCOLO, 2005), esquecendo-se de que há propostas pedagógicas que permitem a vivência das modalidades da Ginástica dentro da escola, com movimentos simples, que ajudam no desenvolvimento do aluno e que permitem que todos sejam incluídos (NISTA-PICCOLO; MOREIRA, 2012).

\section{Dificuldades e alternativas: risco de lesões}

Por outro lado, $11 \%$ dos professores alegaram que a ginástica é uma prática de alto risco para os alunos. Nista-Piccolo (1988) constatou em seus estudos que os docentes não incluíam conteúdos de Ginástica Artística em suas aulas por temerem possíveis acidentes com os alunos e por não saberem ensinar os movimentos ou corrigi-los quando executados erroneamente durante as aulas. Reforça a autora que isso se deve a um despreparo, especialmente no que tange ao desconhecimento dos procedimentos pedagógicos, opinião similar à apontada por Nunomura (1998).

\section{Dificuldades e alternativas: formação inadequada ou insuficiente}

A falta de formação especializada, também com $22 \%$ das respostas, foi apontada como dificuldade. Com respeito à formação inicial, problema apontado por outros estudos (RINALDI; SOUZA, 2003; SCHIAVON, 2003) e que volta à tona nessa pesquisa, Nunomura (2001) afirma que os cursos de graduação em Educação Física, em sua maioria, não 
oferecem subsídios suficientes para o desenvolvimento da Ginástica Artística dentro de um ambiente de ensino, tanto escolar como esportivo. De acordo com Schiavon e Nista-Piccolo (2007, p. 132), "ao analisar as grades curriculares dos cursos de Educação Física, em diferentes faculdades, percebe-se que falta um olhar pedagógico sobre essa modalidade esportiva", limitando-a somente ao aspecto competitivo. No entanto, Nista-Piccolo (2005) faz uma análise comparativa a respeito da grade curricular nos cursos superiores de Educação Física e constata o aumento das disciplinas voltadas para a área da Ginástica nas instituições de ensino.

É possível que o trato mais amplo da Ginástica na formação inicial possa ter contribuído na realidade estudada nessa ocasião, uma vez que $77,5 \%$ dos professores a incluíram no conteúdo das aulas. No entanto, e curiosamente, dos professores que relataram não ensinar Ginástica, a maioria (67\%) se formou depois dessa mudança na grade curricular nas faculdades de Educação Física, apontada por Nista-Piccolo (2005). Sendo assim, é necessário refletir que o aumento das disciplinas gímnicas nas instituições de ensino pode não ser garantia de que a Ginástica se faça presente nas escolas, mesmo porque o aumento na quantidade de disciplinas não necessariamente é acompanhada de qualidade das aulas ministradas no curso superior. Daí advém a urgência de uma efetiva formação continuada e do suporte constante para os professores.

Ao se constatar que o conhecimento insuficiente do ensino da Ginástica, pode colaborar em todas as dificuldades elencadas pelos professores participantes, importante se faz conhecer como se deu a formação específica em Ginástica dos professores participantes na pesquisa. As respostas indicaram a formação inicial ocorrida na universidade, como o principal espaço formativo (70\% das respostas). Vale ressaltar que $10 \%$ dos professores destacaram que a formação recebida na universidade foi "básica" ou "insuficiente". Para $25 \%$ dos professores entrevistados, a formação foi complementada em cursos e eventos específicos da área de Ginástica. Dentre essas possibilidades de formação, cinco professores (P8, P11, P17, P21 e P31) citaram os encontros de formação continuada oferecidos aos professores da rede municipal de Itatiba, o que mostra certa atenção do município a este tema.

O "Professor 10" acredita que "a formação deve ser continuada", e menciona que participa de cursos e eventos com frequência, visando à complementação dos conhecimentos obtidos durante sua formação inicial. Essa posição coincide com a proposta apresentada por Almeida (2005), na qual ressalta que a formação continuada dos professores deve ser parte das políticas públicas para a qualificação do trabalho docente.

Como outras formas de adquirir conhecimento específico, 8\% dos professores relataram ter realizado estágio na área, $5 \%$ fizeram parte de grupos de estudo ou recorrem regularmente a referências bibliográficas para o planejamento das aulas e, finalmente, 5\% tiveram experiências com Ginástica em clubes.

Um depoimento que merece destaque foi apresentado pelo "Professor 11", quando relatou ter realizado estágio em GA, e essa experiência lhe permitiu atuar "sob uma visão pedagógica e não de rendimento". Além do estágio, o mesmo professor salientou ter participado da formação continuada oferecida pela rede municipal de Itatiba, embora na 
opinião de P11: "o curso não é suficiente para quem nunca teve vivência nestes esportes [ginástica], pois é uma atividade que exige bastante cuidado". Esse profissional, como outros que se envolveram no estudo, sugeriu a necessidade de mais cursos de formação continuada, por ser a Ginástica uma atividade de que os alunos gostam.

Em contrapartida, cerca de $23 \%$ dos participantes da pesquisa alegaram não ter recebido formação específica sobre o tema até o momento. Um deles inclusive, o "Professor 27 ", complementou sua resposta alegando que a formação recebida durante a graduação tinha sido insuficiente na área da Ginástica, relato que coincide com os resultados do estudo realizado por Rinaldi e Souza (2003). Mais uma vez a questão da formação inicial aparece como determinante.

\section{Relação entre as dificuldades e as alternativas}

Considerando os professores entrevistados que ministram Ginástica nas aulas de Educação Física escolar, as dificuldades apontadas se configuram conforme exposto na Tabela 3.

Tabela 3 - Dificuldades encontradas pelos docentes para o ensino da Ginástica

\begin{tabular}{lc}
\hline Dificuldades & Porcentagem \\
\hline Falta de material/ equipamento/ aparelhos & 87,1 \\
Formação Inicial insuficiente & 45,2 \\
Falta de apoio da escola & 3,2 \\
Falta de espaço adequado / espaço insuficiente & 12,9 \\
Desinteresse por parte dos alunos & 29,0 \\
Falta de cultura esportiva / conhecimento sobre a ginástica & 3,2 \\
Falta de apoio de estagiário & 6,5 \\
Relevância do conteúdo Ginástica no projeto pedagógico & 3,2 \\
Classes numerosas (quantidade de alunos) & 3,2 \\
Dificuldade no transporte do material & 6,5 \\
\hline
\end{tabular}

Além das opções oferecidas pelo questionário (falta de material, falta de formação, falta de apoio da escola, falta de espaço/espaço insuficiente, desinteresse dos alunos), alguns professores acrescentaram novos itens, na alternativa "outros", conforme exposto e categorizado na Tabela 3. De todas as dificuldades, a mais citada pelos professores foi a falta de material (87\%), o que corrobora as justificativas dadas anteriormente pelos professores dessa pesquisa que não ensinam Ginástica na escola (22,5\%). A falta de formação também teve um número significativo das respostas, apresentando 43\%, o que também é confirmado por Schiavon (2003), que ressalta que o profissional que tem conhecimento saberá criar alternativas para ensinar Ginástica. Nista-Piccolo (2005) também dialoga no 
mesmo sentido, ao afirmar que houve uma mudança nos cursos de graduação, ampliando as disciplinas relacionadas à Ginástica, mas essas alterações ainda não foram suficientes.

Sobre as estratégias utilizadas pelos professores para superar as dificuldades apontadas anteriormente, obteve-se em síntese o resultado exposto na Tabela 4.

Tabela 4 - Estratégias empregadas para o ensino da Ginástica

\begin{tabular}{lc}
\hline Estratégias & Porcentagem (\%) \\
\hline Ensino de elementos da Ginástica durante o aquecimento e/ou alongamento & 6,5 \\
Uso de vídeos e imagens & 29 \\
Adaptação de material/equipamento/aparelhos & 61,3 \\
Adaptação de espaço & 6,5 \\
Ajuda dos alunos durante as atividades & 9,7 \\
Jogos/brincadeiras & 6,5 \\
Organização de Festival Ginástico & 3,2 \\
Apresentação de Trabalho teórico-prático & 6,5 \\
Empréstimo de material/equipamento/aparelhos de outras escolas & 9,7 \\
Suporte de outros professores & 6,5 \\
Consulta a livros / materiais didáticos & 9,7 \\
Confecção de materiais/equipamentos/aparelhos alternativos & 9,7 \\
Motivação dos alunos & 9,7 \\
\hline
\end{tabular}

Ao mesmo tempo em que a falta de material é a principal dificuldade destacada pelos professores, a adaptação de materiais é também a principal alternativa viável destacada por eles $(61,3 \%)$, exemplificada nas respostas com a utilização de bancos, pneus e até mesmo as carteiras/cadeiras de sala de aula, as quais não são propriamente materiais específicos da ginástica, mas podem auxiliar no trabalho. A confecção alternativa de materiais/aparelhos foi mencionada como solução por $10 \%$ dos professores, corroborando as propostas de Schiavon (2005) e Otsuka (2012), que enfatizam ainda que essa opção pode gerar maior envolvimento dos pais/responsáveis e da comunidade nesse processo. Vale ressaltar que a confecção artesanal está atrelada à ausência de materiais específicos, mostrando que essa condição dificulta, porém não impede o ensino da Ginástica.

Devido às limitações da pesquisa não foi possível averiguar quem foi responsável pela confecção do material (se pais, professores em período extraclasse ou mesmo em conjunto com os alunos durante as aulas). De qualquer maneira, esse dado mostra o interesse e a preocupação de alguns professores com o ensino da Ginástica nas aulas de Educação Física escolar.

Além disso, aproximadamente $10 \%$ dos professores disseram emprestar material de outras unidades escolares. Não obstante, a confecção artesanal e o empréstimo não negam a importância e a necessidade de possuir material específico para as aulas, mas, sim, 
evidenciam uma estratégia para não deixar de ensinar. Logo, tanto docentes como instituições não devem deixar de buscar a aquisição de materiais/equipamentos/aparelhos especializados, os quais certamente auxiliam e motivam o ensino da Ginástica (AYOUB, 2007).

Por outro lado, mesmo quando a escola possui material, os questionários registraram a dificuldade de transportá-lo até a quadra ou outros locais onde as aulas são realizadas. Cerca de $10 \%$ dos professores afirmaram solicitar a ajuda dos alunos, nas palavras da Professora 19 que ministra aulas de Educação Física para o ensino fundamental I $\left(1^{\circ}\right.$ ao $5^{\circ}$ ano), em uma escola particular: "Peço ajuda de funcionários, estagiários e até mesmo dos alunos quando são maiores e gostam de ajudar". É importante destacar que a participação dos alunos no processo de preparação, na execução e no fechamento da aula pode ser uma estratégia bastante interessante de envolvê-los, ensinando a transportar o material, a cuidar dele e a armazená-lo da forma correta, como indica Gerling (2009).

O ensino da Ginástica por meio de suporte áudio-visual, como vídeos e imagens, também foi uma estratégia adotada pelos professores (29\%). Conforme Ayoub (1998, p.151) "assistir apresentação de Ginástica Geral, seja através de vídeo ou ao vivo, é uma dimensão essencial para a compreensão dessa atividade". Esse recurso se mostra muito interessante para ser desenvolvido para qualquer manifestação gímnica, configurando-se não apenas como uma alternativa para as dificuldades dos professores, mas, sim, como uma estratégia para ensinar conteúdos conceituais e factuais, contextualizando as diferentes práticas corporais ginásticas.

A adaptação do espaço foi mencionada também como estratégia para superar as dificuldades, nesse caso em apenas $6 \%$ das respostas. Porém, o instrumento utilizado não possibilitou que os professores especificassem como ocorre essa adaptação. Considerando que todas as escolas da cidade possuem quadra poliesportiva, parece que muitos docentes não visualizam esse espaço como um espaço próprio para o ensino da Ginástica (SCHIAVON, 2003). Segundo essa autora, o maior problema não é o espaço ou o material, mas, sim, a falta de conhecimento para poder adaptar os conteúdos aos diferentes contextos e às condições presentes na escola.

Outra estratégia relatada por $6 \%$ dos professores foi a de incluir aspectos técnicos e conceituais da Ginástica durante as sessões de alongamento e aquecimento, parte do que pode ser considerado como "Ginástica de Condicionamento Físico" (SOUZA, 1997), porém não seria o ideal trabalhá-la assim. Dessa forma, como disseram, foi possível "envolver a ginástica com outros esportes mais aceitos" (P1). Essa forma de "disfarçar" ou introduzir a Ginástica não é a mais adequada, pois ela é uma prática corporal que possui conteúdos próprios e merece ser tratada como tal nas aulas de Educação Física escolar, como mostram os argumentos apresentados anteriormente. Trabalhar a Ginástica apenas como parte do aquecimento/alongamento pode contribuir para se criar uma visão reducionista e "utilitária" (como conjunto de exercícios de condicionamento físico), restringindo os conhecimentos dos alunos ao "saber fazer" e, mesmo assim, sem qualquer contextualização. É importante conscientizar os alunos, aos poucos, dos muitos conteúdos e temas da Educação Física escolar, localizando a Ginástica nesse amplo universo de possibilidades, e problematizando-a, a partir das especificidades de cada uma de suas manifestações. 
Também com $6 \%$ das respostas, os professores indicaram utilizar jogos e brincadeiras ginásticos, para criar um ambiente lúdico e motivante (MATEU, 2000). Nesse contexto, um dos professores participantes salienta que é permitido aos alunos "explorar os movimentos básicos e elementares [da ginástica] sem o comprometimento técnico" (P20). Schiavon (2003) explica que modalidades gímnicas competitivas também podem ser desenvolvidas no ambiente escolar, com ênfase na finalidade educativa, priorizando as suas vivências, sem fins competitivos, ou com vivências pedagógicas da competição e, por consequência, o desenvolvimento dos alunos.

Por fim, outras duas estratégias foram mencionadas: a busca de informações em livros e outros materiais (10\%), o que revelou a preocupação de atualizar os conhecimentos; e a troca de experiências com outros professores (7\%).

Diante das dificuldades encontradas e das estratégias apontadas pelos professores, pode-se realizar uma comparação desses dois pontos, como visto no Quadro1.

Quadro 1 - Comparativo entre as dificuldades encontradas e as estratégias utilizadas pelos docentes para sua superação

\begin{tabular}{ll}
\hline Dificuldades & Estratégias \\
\hline Falta de material/ equipamento/ aparelhos & $\begin{array}{l}\text { Adaptação, criação e empréstimo de material } \\
\text { Consulta à bibliografia; troca de experiência } \\
\text { com outros professores } \\
\text { (não relacionado) }\end{array}$ \\
$\begin{array}{l}\text { Falta de apoio da escola } \\
\text { Falta de espaço adequado / espaço insuficiente }\end{array}$ & $\begin{array}{l}\text { Adaptação dae espaço } \\
\text { Motivação dos alunos; uso de vídeos/imagens; } \\
\text { organização de festival; proposta de trabalho } \\
\text { teórico prático; jogos e brincadeiras }\end{array}$ \\
$\begin{array}{ll}\text { Falta de cultura esportiva / conhecimento sobre } \\
\text { a Ginástica }\end{array}$ & $\begin{array}{l}\text { Aquecimento/alongamento; jogos e } \\
\text { brincadeiras }\end{array}$ \\
$\begin{array}{l}\text { Falta de apoio de estagiário } \\
\text { Relevância do conteúdo Ginástica no projeto } \\
\text { pedagógico }\end{array}$ & $\begin{array}{l}\text { (não relacionado) } \\
\text { Classes numerosas (quantidade de alunos) }\end{array}$ \\
$\begin{array}{l}\text { Dificuldade no transporte do material } \\
\text { Ajuda dos próprios alunos }\end{array}$ \\
\hline
\end{tabular}

\section{Manifestações gímnicas ensinadas}

Dentre as alternativas oferecidas no questionário, sobre as manifestações gímnicas ensinadas (Acrobática, Rítmica, Artística, Aeróbica esportiva, Trampolim, Geral), a maior frequência registrada foi da Ginástica Geral - desde 2007 denominada Ginástica Para Todos - com $77 \%$ das respostas dos professores. Na sequência, aparecem a Ginástica 
Artística com $61 \%$ das respostas e a Ginástica Rítmica com 58\%. A Ginástica Acrobática é lecionada por $42 \%$ dos docentes e, por fim, a Ginástica de Trampolim, com 6,5\% das respostas. Nota-se, portanto, que existe uma predominância pela Ginástica não competitiva ou demonstrativa (Ginástica Geral/Ginástica para todos), seguida das modalidades de Ginástica Artística e Ginástica Rítmica, frequentemente apontadas como as mais "populares" entre os professores. Segundo Lima (2010), é muito possível que a ênfase nessas modalidades tenha relação com os conhecimentos oferecidos na formação inicial dos docentes, em cursos superiores da Região Metropolitana de Campinas (RMC), onde 65\% dos professores realizaram sua graduação, indicando as mesmas tendências.

Não obstante, a falta de material (cama-elástica; mini-trampolim; duplo-mini-trampolim) certamente acarreta dificuldade de abordar Ginásticas que possuem características mais diretamente relacionadas a aparelhos, como a Ginástica de Trampolim. O mesmo não se pode dizer da Ginástica Acrobática que independe de material e certamente relaciona-se à questão da formação inicial destacada por Lima (2010). Possivelmente essa seja uma das grandes "novidades" apontadas nesse estudo, considerando que a Ginástica Acrobática é ainda uma modalidade periférica, quando o assunto é ensino da Ginástica na escola, como apontam Merida, Nista-Piccolo e Merida (2008).

Todos os dados apontados pelos professores devem ser considerados, pois eles se refletem direta e diariamente em suas práticas pedagógicas. Mas o mais relevante é a necessidade da formação continuada desses professores, visto que esses momentos abrem novas possibilidades, trazem alternativas e diversificam o contexto na prática. O conhecimento é o "material" mais importante a ser oferecido aos professores, para que possam desenvolver estratégias diante sua realidade.

\section{CONCLUSÕES}

Observa-se nesse estudo que, ao menos no município de Itatiba-SP, o ensino da Ginástica no âmbito escolar é uma realidade na maioria das instituições, contrapondo-se a diversos estudos realizados há mais de uma década e que mostravam a quase inexistência desse conteúdo nas práticas pedagógicas escolares. Assim, nossos dados mostram um cenário distinto, com lenta, porém importante mudança neste panorama.

Embora a Ginástica seja ensinada pela maioria dos professores entrevistados $(77,5 \%)$, ficou nítida a necessidade de ampliar/qualificar seus conhecimentos, quer na formação inicial, quer por meio da formação continuada. Um fato que deve ser observado com atenção pelas universidades e autoridades locais (municipais), regionais e estaduais (secretarias de educação).

De um modo geral, entende-se que é preciso insistir na possibilidade de abordar as práticas gímnicas, mesmo quando for necessária a utilização de materiais alternativos (não oficiais), e a adaptação dos espaços, pois, apesar disso, podem-se obter resultados positivos, como destacou Schiavon (2005) há mais de uma década. 
julho/2017

Por fim, o caminho ainda é longo e difícil para obter as melhorias satisfatórias e para que a ginástica seja uma realidade nas escolas, porém a realidade estudada revela indícios de melhoras significativas, ao ser comparado com os dados vinculados entre 1990 e 2000. Neste sentido, o município de Itatiba-SP pode sentir-se privilegiado, pois apresenta um panorama animador, embora ainda não ideal, no que se refere ao ensino da Ginástica nas aulas de EFE.

\section{REFERÊNCIAS}

ALMEIDA, R. S. A ginástica na escola e na formação de professores. 2005. 213f. Tese (Doutorado)-Faculdade de Educação, Universidade Federal da Bahia, Salvador-BA. Disponível em: < http://www.lepel.ufba.br/TESES/A\%20GIN\%C1STICA\%20NA\%20 ESCOLA $\%$ 20E $\%$ 20NA \% 20FORMA $\%$ C7 \% C3O \% 20DE $\%$ 20PROFESSORES $\% 20-\% 20$ ROSEANE\%20ALMEIDA.pdf>. Acesso em: 19 out. 2013.

AYOUB, Eliana. A ginástica geral na sociedade contemporânea: respectivas para a Educação Física escolar. 1998. 187f. Tese (Doutorado) - Universidade Estadual de Campinas, Faculdade de Educação Física, Campinas, SP. Disponível em: < http://libdigi. unicamp.br/document/?code =vtls000134681 > . Acesso em: 16 jul. 2013.

AYOUB, Eliana. A ginástica geral e Educação Física escolar. 2. ed. Campinas: Unicamp, 2007.

BARDIN, Laurence. Análise de conteúdo. São Paulo, SP: Edições 70, 2011.

BERTOLINI, Cláudia Mara. Ginástica Geral na escola: uma proposta pedagógica desenvolvida na rede estadual de ensino. 2005. 142f. Dissertação (Mestrado) - Universidade Estadual de Campinas, Faculdade de Educação Física, Campinas, SP. Disponível em: < http:// www.bibliotecadigital.unicamp.br/document/?code =vtls000357255>. Acesso em: 16 abr. 2013.

BONETTI, A. Ginástica: em busca de sua identificação no âmbito escolar. Dissertação (Mestrado) - Centro de Desportos, Universidade Federal de Santa Catarina, FlorianópolisSC, 1999.

COLETIVO DE AUTORES. Metodologia do Ensino de Educação Física. São Paulo: Cortez, 1992.

DA SILVA, J. V. P. Prática pedagógica em educação física nos anos iniciais do ensino fundamental. Pensar a Prática, Goiânia, v. 16, n. 1, p. 1319, Jan-Mar. 2013.

FERREIRA, Janaina da Silva; SANTOS, José Henrique; COSTA, Bruno de Oliveira. Perfil de formação continuada de professores de Educação Física: modelos, modalidades e contributos para a prática pedagógica. Revista Brasileira de Ciências do Esporte, v. 37 (3), Jul-Set.2015, p. 289-298.

GERLING, Ilona. Teaching children's gymnastics. London: Meyer \& Meyer, 2009.

LIMA, Helaine Cristina Ferreira. Construção da docência: trajetórias de professores de ginástica no ensino superior. 2010. 134p. Dissertação (Mestrado)-Pontifícia Universidade Católica de Campinas, Centro de Ciências Humanas e Sociais Aplicadas, 
Programa de Pós-Graduação em Educação, Campinas, 2010. Disponível em: < http://www.bibliotecadigital.puc-campinas.edu.br/tde_arquivos/3/TDE-2011-0221T082825Z-1656/Publico/Helaine\%20Cristina\%20Ferreira\%20Lima.pdf $>$. Acesso em: 17 ago. 2013.

LOPES, Priscila. Confecção de aparelhos alternativos para Ginástica Rítmica: a experiência na disciplina Ginástica I do curso de Educação Física da UFVJM. In: FÓRUM INTERNACIONAL DE GINÁSTICA GERAL, 6., Anais..., Campinas, SP: FEF/UNICAMP, 2012. p. 326-333.

MACEDO, L. F. D. Confecção de equipamentos alternativos para Ginástica Artística: uma possibilidade real. In: In: FÓRUM INTERNACIONAL DE GINÁSTICA GERAL, 6., Anais...-, Campinas, SP: FEF/UNICAMP, 2012. p. 333-339

MATEU, M. S. 1300 ejercicios y juegos aplicados a las atividades gimnásticas. Barcelona: Editorial Paidotribo, 2000.

MERIDA, Fernanda; NISTA-PICCOLO, Vilma Lení; MERIDA, Marcos. Redescobrindo a Ginástica Acrobática. Movimento (UFRGS. Impresso), v. 14, p. 155-180, 2008.

NISTA PICCOLO, Vilma Lení. Atividades físicas como proposta educacional para 1a.fase do 1o. grau. 1988. Dissertação (Mestrado)-Faculdade de Educação, Universidade Estadual de Campinas, Campinas, 1988.

NISTA-PICCOLO, Vilma Lení. Pedagogia da Ginástica Artística. In: NUNOMURA. Myrian. (Org.). Compreendendo a Ginástica Artística. São Paulo: Phorte, 2005. p. 27-36.

NISTA-PICCOLO, Vilma Lení; MOREIRA, Wagner Wey. Esporte como conhecimento e prática nos anos iniciais do ensino fundamental. 1 ed. São Paulo, SP: Cortez, 2012.

NUNOMURA, Myrian. Segurança na Ginástica Olímpica. Motriz (Rio Claro) (Cessou em 2006), Rio Claro, v. 4, n. 2, p. 65-68, 1998.

NUNOMURA, Myrian. Técnico de ginástica artística: uma proposta para a formação profissional. 2001. 181p. Tese (Doutorado) - Universidade Estadual de Campinas, Faculdade de Educação Física, Campinas, SP. Disponível em: < http://libdigi.unicamp. br/document/?code = vtls000223208>. Acesso em: 31 jul. 2013.

OLIVEIRA, Amauri A. Bássoli; KRAVCHYNCHYN, Cláudio; MOREIRA, Evando Carlos; PEREIRA, Raquel Stoilov. Ensinando e aprendendo esportes no Programa Segundo Tempo. Maringá: Eduem, 2011.

OTSUKA, Marcos Minoru. Pluralidade corporal e ginástica: o contexto escolar e materiais alternativos. Dissertação (Mestrado) - Centro Universitário Univates, Ambiente e Desenvolvimento, Lageado, RS. Disponível em:

< https://www.univates.br/bdu/bitstream/10737/286/1/MarcosOtsuka.pdf > . Acesso em 15 out. 2015.

PARANÁ (Estado). Diretrizes Curriculares da Educação Básica para Educação Física do Estado do Paraná. SEED, Curitiba - 200

POLITO, Beatriz Spina. A ginástica artística na escola: realidade ou possibilidade? Monografia (Trabalho de conclusão de curso)- Faculdade de Educação Física, Universidade Estadual de Campinas, Campinas, SP, 1998. Disponível em: < http:// www.bibliotecadigital.unicamp.br/document/?code $=000337373>$. Acesso em: 11 de out. 2012. 
julho/2017

RINALDI, leda Parra Barbosa; SOUZA, Elizabeth Paoliello Machado. A ginástica no percurso escolar dos ingressantes dos cursos de licenciatura em educação física da Universidade Estadual de Maringá e da Universidade Estadual de Campinas. Revista Brasileira de Ciências do Esporte, v. 24, n. 3, p.159-173, maio 2003. Disponível em:

< http://www.rbceonline.org.br/revista/index.php/RBCE/article/view/769>. Acesso em: 12 out. 2012.

RUSSELL, Keith; NUNOMURA, Myrian. Uma alternativa de abordagem de ginástica na escola. Revista da Educação Física/UEM, Maringá, v. 13, n. 1, p. 123-127, 1. sem. 2002.

SÃO PAUlO (Estado). Secretaria de Educação. Proposta Curricular do Estado de São Paulo, São Paulo, 2008.

SCHIAVON, Laurita Marconi. O projeto crescendo com a ginástica: uma possibilidade na escola. 2003. 185p. Dissertação (Mestrado) - Universidade Estadual de Campinas, Faculdade de Educação Física, Campinas, SP. Disponível em: < http://libdigi.unicamp. br/document/?code = vtls000300852 > . Acesso em: 10 out. 2012.

SCHIAVON, Laurita Marconi. Materiais alternativos para a Ginástica Artística. In: NUnOMURA. M. (Org.). Compreendendo a Ginástica Artística. São Paulo: Phorte, 2005. p. 169-181.

SCHIAVON, Laurita Marconi; NISTA-PICCOLO, Vilma Lení. Desafios da ginástica na escola. In: MOREIRA, E. C. Educação Física escolar: desafios e propostas 2. Jundiaí, SP: Fontoura, p. 35-60, 2006.

SCHIAVON, Laurita Marconi; NISTA-PICCOLO, Vilma Lení. A ginástica vai à escola. Movimento, Rio Grande do Sul, v. 13, n. 3, jul./ago./set. 2007. Disponível em: < http:// seer.ufrgs.br/Movimento/article/view/3572 >. Acesso em: 11 out. 2012.

SCHIAVON, Laurita Marconi; NISTA-PICCOLO, Vilma Lení. Imagynação: uma experiência de projeto extracurricular de Ginástica Rítmica. In: PAOLIELLO, E.; TOLEDO, E.. Possibilidades da Ginástica Rítmica.1. ed. São Paulo: Phorte, 2010. p. 332-357.

SAMPAIO, R.F.; MANCINI, M.C. Estudos de revisão sistemática: um guia para síntese criteriosa da evidência científica. Revista Brasileira de Fisioterapia, São Carlos, v. 11, n. 1, p. 83-89, jan./fev. 2007

SOUZA, Elizabeth Paoliello Machado. Ginástica geral: uma área do conhecimento da educação física. 1997. Tese (Doutorado) - Universidade Estadual de Campinas, Faculdade de Educação Física, Campinas, SP, 1997. Disponível em: (http://libdigi. unicamp.br/document/?code=vtls000114740). Acesso em: 15 abr. 2015.

SOUZA JÚNIOR, Marcílio Barbosa Mendonça de; DE MELO, Marcelo Soares Tavares; SANTIAGO, Maria Eliete. A análise de conteúdo como forma de tratamento dos dados numa pesquisa qualitativa em educação física escolar. Movimento (ESEF/UFRGS), Porto Alegre, v. 16, n. 3, p. 29-47, jun. 2010.

THOMAS, J.R.; NELSON, J. K. Métodos de pesquisa em atividade física. 3. ed. Porto Alegre: Artmed, 2002.

Recebido em: junho/2016 Aprovado em: outubro/2016 